[Agr. Biol. Chem., Vol. 36, No. 3, p. $521 \sim 522$, 1972]

\title{
Dihydrosterigmatocystin and Dihydrodemethylsterigmatocystin, New Metabolites from Aspergillus versicolor
}

Sir:

Sterigmatocystin, ${ }^{11}$ 5-methoxysterigmatocys$\operatorname{tin}^{2 !}$ and demethylsterigmatocystin ${ }^{3 \prime}$ have been previously isolated from mycelium of Aspergillus versicolor (Vuillemin) Tiraboshi. In continuation of our work on the metabolites of mold, we have recently isolated two new minor metabolites and shown them to be dihydrosterigmatocystin (I) and dihydrodemethylsterigmatocystin (II). The structural elucidation of these metabolites are reported here.

Compound (I) forms pale yellow needles, $\mathrm{mp} 230^{\circ} \mathrm{C}$ (decompd.), $[\alpha]_{\mathrm{D}}^{20}-311.7^{\circ} \quad(c=0.85$, $\left.\mathrm{CHCl}_{3}\right)$. Anal. Found: $\mathrm{C}, 66.42 ; \mathrm{H}, 4.14 ; \mathrm{m} / \mathrm{e}$ : $326\left(\mathrm{M}^{+}\right)$. Calcd. for $\mathrm{C}_{18} \mathrm{H}_{14} \mathrm{O}_{6}: \mathrm{C}, 66.25 ; \mathrm{H}$, 4.32\%: M.W.326. UV $\lambda_{\text {max }}^{\mathrm{EtOH}} \mathrm{m} \psi(\varepsilon): 233(27,600)$, $247(32,200), 325(16,600)$. It yields a green ferric reaction in ethanol and has UV spectrum similar to that of sterigmatocystin. IR spectrum showed band at 1645 and $1620 \mathrm{~cm}^{-1}$ indicating the presence of $\gamma$-pyron system in I. NMR spectrum of I in deuterochloroform showed two singlet resonance at $\tau 6.01(3 \mathrm{H})$ indicative of methoxyl group and at $\tau-3.3$ (1H) due to the proton of chelated hydroxyl group. Additional signal for four protons at ₹ $3.60(1 \mathrm{H}$, singlet), $3.30(1 \mathrm{H}$, doublet of doublets, $J=8.5$ and $1.0 \mathrm{cps}), 3.24(1 \mathrm{H}$, doublet of doublets, $J=8.5$ and $1.0 \mathrm{cps})$ and $2.45(1 \mathrm{H}$, triplet, $J=8.5 \mathrm{cps}$ ) were assigned to be aromatic protons. The remaining six protons at $\tau 7.70$ (2H, multiplet), 6.32 ( $1 \mathrm{H}$, multiplet), $5.80(2 \mathrm{H}$, multiplet) and $6.46(1 \mathrm{H}$, doublet, $J=5.5 \mathrm{cps})$ were assumed to be six protons of tetrahydrodifurano ring system. The evidence presented above suggested that I may be dihydrosterigmatocystin. Confirmation of this proposal was done by synthesis of the compound, in which catalytic hydrogenation of sterigmatocystin yielded dihydro-derivative, identical with $I$ in all respects.

Compound (II) forms pale yellow needles when recrystallized from acetone, $\mathrm{mp} 202^{\circ} \mathrm{C}$ (decompd.), $[\alpha]_{\mathrm{D}}^{25}-376.6^{\circ} \quad\left(c=0.90, \mathrm{CHCl}_{3}\right)$. Anal. Found: C, 65.16; H, 3.92; m/e: $312\left(\mathrm{M}^{+}\right)$. Calcd. for $\mathrm{C}_{17} \mathrm{H}_{12} \mathrm{O}_{6}: \mathrm{C}, 65.38 ; \mathrm{H}, 3.87 \% ; \mathrm{M} . W$. 312. UV $\lambda_{\mathrm{mian}}^{\mathrm{EtOH}} \mathrm{m} \mu(\varepsilon): 233(26,800), 250(33,100)$, $259(30,300), 335(19,400)$. It yields a green ferric reaction in ethanol and has UV spectrum similar to that of demethylsterigmatocystin, indicating that xanthone nucleus is present. IR spectrum showed band at 1659 and $1625 \mathrm{~cm}^{-1}$ indicating the presence of $\gamma$ pyrone system in II. NMR spectrum of II in deuterochloroform showed two singlet resonance at $\tau-1.84(1 \mathrm{H})$ and $-2.10(1 \mathrm{H})$ due to the protons of chelated hydroxyl group. Additional signal for four protons at $\tau 3.74$ $(1 \mathrm{H}$, singlet $), 3.28(1 \mathrm{H}$, doublet of doublets, $J=8.5$ and $1.0 \mathrm{cps}), 3.18(1 \mathrm{H}$, doublet of doublets, $J=8.5$ and $1.0 \mathrm{cps}$ ) and $2.45(1 \mathrm{H}$, triplet, $J=8.5 \mathrm{cps}$ ) were assumed to be aromatic protons. A comparison of II and demethylsterigmatocystin shows the similarity in aromatic protons of the two compounds. The remaining six protons at $\tau 7.75(2 \mathrm{H}$, multiplet), 6.30 ( $1 \mathrm{H}$, multiplet), $5.89(1 \mathrm{H}$, multiplet), $5.84(1 \mathrm{H}$, multiplet) and $3.53(1 \mathrm{H}$, doublet, $J=5.5 \mathrm{cps})$ were assigned to the six protons of tetrahydrodifurano ring system and this assignment is supported by the result of spin decoupling experiment of II. From the data obtained it can be concluded that II may be dihydroderivative of demethylsterigmatocystin. For comfirmation, dihydrodemethylsterigmatocystin identical with II in all respects was syn- 
thesized from demethylsterigmatocystin by hydrogenation with platinum oxide catalyst.

A synthetic 5-hydroxydihydrosterigmatosystin was shown to be a direct precursor of aflatoxins $\mathrm{B}_{2}$ and $\mathrm{G}_{2}{ }^{3}$ in Aspergillus parasiticus. The chemical conversion of $\mathrm{O}$-methyldihydrosterigmatocystin into dihydroaspertoxin has been also reported. ${ }^{4}$ The isolation of these dihydrodifuroxanthones, I and II, from Asp. versicolor would indicate the possibility of biological conversion of sterigmatocystin into aflatoxins and aspertoxin.

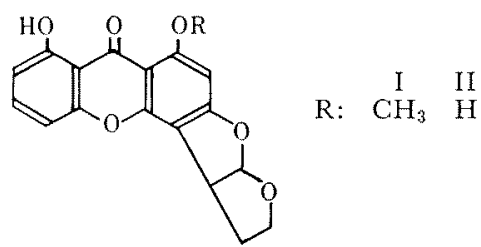

We wish to thank Dr. G. Sunagawa, Central Research Laboratories, Sankyo Co., Ltd., for elemental analyses and measurement of NMR spectra.

\section{REFERENCES}

1) Y. Hatsuda and S. Kuyama, Nippon Nogeikagaku Kaishi, 28, 989 (1954); Y. Hatsuda, S. Kuyama and N. Terashima, ibid., 28, 992 (1954); E. Bullock, J. C. Roberts and J. G. Underwood, J. Chem. Soc,, 1962, 4179; N. Tanaka, Y. Katsube, Y. Hatsuda, T. Hamasaki and M. Ishida, Bull. Chem. Soc, Japan, 43, 3635 (1970).

2) J. S. E. Holker and S. A. Kagal, Chem. Comm., 1968, 1574 .

3) G. C. Elsworthy, J. S. E. Holker, J. M. McKeown, J. B. Robinson and L. J. Mulheirn, ibid., 1970, 1069.

4) R. D. Hutchison and C. W. Holzapfel, Tetrahedron, 27, 425 (1971).

Yuichi Hatsuda

Takashi HAMASAKI

Masayoshi IsHIDA

Kuniaki MATSUI

Shinichiro HARA

Faculty of Agriculture,

Tottori University,

Tottori, Japan

Received January 7, 1972 